\title{
Greening states and societies: from transitions to great transformations
}

\section{Robyn Eckersley}

To cite this article: Robyn Eckersley (2020): Greening states and societies: from transitions to great transformations, Environmental Politics, DOI: 10.1080/09644016.2020.1810890

To link to this article: https://doi.org/10.1080/09644016.2020.1810890
( $) 2020$ The Author(s). Published by Informa UK Limited, trading as Taylor \& Francis Group.

\section{曲 Published online: 30 Aug 2020.}

Submit your article to this journal $\pi$

\section{Џlll Article views: 1582}

Q View related articles $₫$

View Crossmark data $\asymp$ 


\title{
Greening states and societies: from transitions to great transformations
}

\author{
Robyn Eckersley (D) \\ Discipline of Political Science, School of Social and Political Sciences, University of Melbourne, \\ Melbourne, Australia
}

\begin{abstract}
This article examines the limits and potential of the state in orchestrating sustainability transitions from the standpoint of critical theory on the green state. Two interrelated questions are posed. First, to what extent are democratic capitalist states necessarily compromised in their functional capacity to orchestrate ecological sustainability? Second, in light of this analysis, how can a theory of the green state that claims to be critical and transformative, rather than merely problem-solving, provide practical guidance to state and societal change agents in approaching the political challenges of ecological transition? A critical method for approaching these challenges is outlined, encompassing conjunctural analysis followed by situated, critical problem solving, which is geared to identifying the 'next best transition steps' with the greatest long-term transformational potential. The method is briefly illustrated in relation to the critical conjuncture presented by the coronavirus pandemic.
\end{abstract}

KEYWORDS Green state; socio-technical transitions; just transitions; conjunctural analysis; critical problem-solving

\section{Introduction}

Research on sustainability transitions has exploded over the last decade. Most prominent is the burgeoning scholarship on transitions in socio-technical systems (e.g., Köhler et al. 2019). However, as Bäckstrand and Kronsell (2015) have observed, until very recently there has been relatively little discussion of the transition process in the literature on the green state, with Hysing (2015) suggesting the green state is 'lost in transition'. Moreover, recent assessments of the prospects of actually-existing states evolving into fullyfledged green states are more pessimistic than they were a decade ago (Bailey 2015, Mol 2016, Paterson 2016, Hausknost and Hammond 2020).

This paper re-examines and further develops the critical theory of the green state with the aim of drawing out both the potential and limits of the state in orchestrating ecological sustainability transitions. Two inter-related 
questions guide the re-examination. First, to what extent are states necessarily compromised in their functional capacity to orchestrate ecological sustainability, and therefore ecological transitions? Second, in light of this analysis, how can a theory of the green state that claims to be critical and emancipatory, rather than problem-solving in a way that upholds the status quo, provide practical guidance to state policy makers and societal change agents in approaching the transition process?

The first question is addressed through a critical appraisal of critical theories of the environmental state, which converge on the conclusion that it is functionally incapable of giving priority to ecologically sustainability. The second question is both methodological and practical, and it is approached by revisiting and critically reworking Robert Cox's influential distinction between critical theory and problem-solving (Cox 1981, p. 130). Throughout this discussion, the term 'environmental state' is used in an analytic-descriptive sense to refer to the environmental functions and activities of actually-existing democratic capitalist states while the term 'green state' refers to an ecologically-inspired normative ideal of the state.

According to Cox, the purpose of critical theory is to render visible and problematise social structures of domination which have hitherto been backgrounded and depoliticised (1981, p. 128). Problem-solving, in contrast, refers to policies that seek to ameliorate problems in ways that work with the grain of such social structures, which remain backgrounded (Cox 1981, p. 128-129). The critical theory of the green state built on this critical tradition of inquiry by grounding it in critical political ecology (CPE), which highlights and problematises the linkages between the domination and exploitation of people and nonhuman nature (Eckersley 2004). However, this theory did not grapple with the immediate political challenges of transition since its primary purpose was to make explicit and defend a normative account of the state that would be more institutionally predisposed to furthering ecological sustainability. Given that states remain ill-disposed or at best weakly disposed towards this project, then the methodological challenge is how to approach the transition challenge in ways that can gain political traction while also being transformative and not merely ameliorative.

The argument unfolds in three sections. First, to prepare the ground for the analysis, a distinction is drawn between transition and transformation as an analytical tool for conceptualising and evaluating the depth and direction of change towards ecological sustainability. This section also identifies what states can uniquely do, or do better than other institutions and organisations, in orchestrating ecological transitions. Section two critically examines neo-Marxist and neo-Weberian critical theories of the environmental state. Through a sympathetic critique of these functionalist analyses a more historicist understanding of the state is shown to be more fruitful in approaching the political challenge of 
transition. Section three develops a two-step critical method for approaching the transition challenge: conjunctural analysis followed by situated, critical problem-solving in particular state-society complexes. Critical problem-solving is geared to identifying the 'next best transition steps' with the greatest transformational potential towards ecological sustainability. The virtues of this method are briefly illustrated through a discussion of the critical conjunctures presented by the novel coronavirus pandemic. The conclusion draws together the main threads of the argument.

\section{Ecological transition versus green transformations}

The terms 'transition' and 'transformation' are sometimes used interchangeably. However, here I draw on Linnér and Wibeck's distinction between the two: 'transition is rooted in the notion of a passage, "going across" from one state to another, whereas transformation refers to "change in form or shape", which is captured in the concept of metamorphosis, such as the transformation from pupa to caterpillar and then to butterfly (Linnér and Wibeck 2019, p. 25; see also Scoones et al. 2015). The burgeoning research on sociotechnical transitions, most notably the multi-level perspective (MLP), has concentrated mainly on the former. According to the MLP, a socio-technical system is a stable alignment of certain technologies, social practices, cultural meanings, public policies, business models, markets, and infrastructures that provides societal functions or end-use services such as energy, food and transport (Geels 2019, p. 187). A socio-technical transition involves a shift from one system of provisioning to another. As Meadowcroft notes, ' $\mathrm{t}$ ] he idiom of transition seems to promise closure' (2005, 490); this assumes a 'before' and an 'after' and 'a period of flux, the passage of time and endpoints with respect to which the transition is defined' (Meadowcroft 2005 , p. 489). In contrast, the general shift from feudalism to industrial capitalism was, as Polanyi (1944-2001) described it, a 'Great Transformation' that saw the complete obliteration of one type of social formation and its replacement with another. Central to this process was the rise of socially disembedded, 'self-regulating' markets and the commodification of land and labour. This transformation also saw major non-linear changes not only in class relations but also in the functions and purposes of states, cultural understandings, social identities, social mobility, energy and resource exploitation, and material flows. Given the risk of civilisational collapse from the irreversible and harmful changes occurring, from local ecosystems to Earth systems, a 'great green transformation' would also require changes of this order. From the normative standpoint of CPE this would require a transformation of states, societies and markets to ensure 
ecologically sustainable and socially equitable material-energy flows in a post-growth economy (e.g. Koch 2020).

Of course, it is impossible to draw a bright line between socio-technical transitions and societal transformations and in any event an accumulation of the former feeds into the latter (Stirling 2015). Moreover, the transformations tracked by Polanyi, especially the rise of self-regulating markets, set off a dynamic of ongoing change, with no closure. Nonetheless, the analytical distinction is useful for two reasons. First, it provides a way of understanding and critically evaluating both the depth and direction of societal change that is set in train with any discrete transition covering one domain of social provisioning. That is, some socio-technical transitions may be transformational from the standpoint of the relevant socio-technical system, but not from the standpoint of the larger social formation. For example, if a new renewable energy system for the power grid simply docks into a capitalist growth economy, then, other things being equal, it is likely to produce a 'rebound effect' whereby the increase in economic productivity drives increasing material consumption, emissions and waste generation in other sectors. However, depending on how transitions to renewable energy are structured, and how they articulate with other transitions, they may help to catalyse societal innovation, new forms of collective ownership and/or democratic management and reductions in material and energy flows in other sectors.

Second, the distinction provides a basis for assessing the degree which ecological transitions and green transformations can (or ought to) be fully planned, as distinct from facilitated and accelerated, by states. There was no blueprint for the industrial revolution, and its drivers were many and varied. States did not plan or initiate the Great Transformation but they played a key role in facilitating and accelerating it by, for example, creating and protecting new forms of private property (such as share ownership of joint stock companies), facilitating and regulating capital accumulation through the banking system, and upholding the law of contract. Likewise, if there is to be a 'great green transformation', then its sources and drivers will be many and varied, spanning societies and states. Nonetheless, states can do a great deal to facilitate societal transformations by orchestrating and/or enabling multiple socio-technical transitions (including food, water, energy, transport, housing etc.) at the national and sub-national levels in a broadly similar direction. Indeed, no other institution can match the state's regulatory capacity to scale-down and redirect material flows and re-embed markets in socio-ecological communities. Nor is there any other institution with the resources and financial transfer mechanisms to provide social welfare and address inequalities and injustices on the scale of states, and this makes them central to managing the unavoidable dislocations that will occur in the transition process. 
Of course, this is a significant challenge for states, which have a long history of aiding and abetting environmental destruction. So before turning to how a critical theory of the green state might approach the political challenges of ecological transitions, it is necessary to examine the logically prior question: to what extent are states capable of ushering in ecologically sustainability given their many contradictory roles?

\section{The eternally compromised environmental state?}

The core claim of neo-Marxist critiques of the environmental state is that governments, as state managers, are trapped in perpetually balancing, without ever resolving, the contradictions between the imperatives of capital accumulation (to keep the state and economy afloat by providing taxation revenue and employment) and democratic legitimation (to respond to public environmental concerns in order to legitimate and maintain political power) (e.g. Paterson 2016). For so long as states remains fiscally parasitic on private capital accumulation, and especially when they become heavily indebted, we can expect states to deal with this dilemma by avoiding degrowth. As Paterson puts it, 'a green state is ... impossible, since the state as we know it and capitalism (for which accumulation is the basic premise) are historically and structurally co-existent' (Paterson 2016, p. 6). Bailey (2015) has recast the state accumulation-legitimation dilemma as a trilemma for the environmental state: that it is impossible simultaneously to orchestrate degrowth, maintain the fiscal viability of the state, while also expanding the environmental functions of the state.

Neo-Marxist accounts conceptualise capitalist states and societies as mutually constitutive and mutually dependent on increasingly debt-driven economic growth. The only way to resolve the contradiction between the state's accumulation and legitimation imperatives is to break this dependence by moving to a post-capitalist state and society that is no longer debtdriven and growth dependent (e.g. Bailey 2020). Until this occurs, the best that governments can do is work with the grain of the accumulation imperative by developing greener strategies of capital accumulation, mainly on the supply-side, by promoting greener technologies (technologically-oriented ecological modernisation) and 'green growth' or, in the language of the French regulation school, greener 'regimes of accumulation' (Paterson 2016). Yet these strategies are ecologically limited since they can only produce a relative rather than absolute decoupling of economic growth from material-energy consumption and emissions/waste/pollution production (e.g. Hickel and Kallis 2019).

Moreover, the wave of economic liberalisation that began in the 1980s has seen the ebbing of the Keynesian welfare state and the rise of the neoliberal or competition state (Cerny 2010). According to Cerny, the competition state 
has become increasingly institutionalized in pursuit of not just a more internationally competitive national economy but also the broader goal of 'maintaining and promoting competitiveness in a world marketplace and multi-level political system' (2010, p. 6). In liberalizing and creating new global capitalist markets, states also transformed themselves in ways that have made it harder for them to respond to environmental demands, other than by 'neoliberalising nature' (Castree 2008, Katz-Rosene and Paterson 2018, chapter 6) by creating new markets and property rights in pollution or pricing ecosystems services.

Whereas the neo-Marxist critiques of the state focus on the functional interdependencies between capitalist state and capitalist societies, neoWeberian critiques argue that the state is also constrained by a set of finite functional imperatives that are rooted in the self-maintenance needs of the state itself to ensure its control of territory and people (Dryzek et al. 2003, Hausknost 2020). While these theories also understand states in relation to their societies (since Weber also understood that state power must be socially legitimated), they nonetheless insist that states have their own independent imperatives, not all of which align with the needs of capital or indeed society. Together, these functional imperatives work as system boundaries, providing an 'invisible glass ceiling' of socio-ecological transformation, which means they cannot be 'transgressed without first changing the underlying structure and identity of the [state] system itself (Hausknost 2020, p. 19; see also Douglas 2020).

For Hausknost (2020, p. 20-21), building on Dryzek et al. (2003), this glass ceiling is the result of the workings of five imperatives for the democratic welfare state: the provision of social order, external defence, revenue raising, the promotion of capital accumulation, and democratic legitimation. Notably, the state's new environmental functions are not seen as representing a new state imperative that is essential to being a state; rather, it is simply the result of the workings of the legitimation imperative (2020, p. 24). Moreover, no single state imperative can be pursued in ways that risk negating any other imperative (Hausknost 2020, p. 21), which rules out the prospect of sustainability emerging as an overriding imperative. Nor can the problem be solved by getting rid of existing political elites (Hausknost 2020, p. 23). Even a new Green Party government with a strong commitment and electoral mandate to pursue a concerted series of socio-ecological transitions would be similarly constrained by conflicting imperatives.

For Hausknost, the only circumstance when states might be expected to pursue a deeper socio-ecological transformation is when the impacts of systemic unsustainability accumulate and directly endanger the immediate lifeworld of citizens to such a degree that states are forced to respond in more far reaching ways $(2020$, p. 26). However, by the time the glass ceiling is broken in this way, it is likely to be too late for effective preventative 
measures, leaving states to focus on damage limitation and adaptation (Hausknost 2020, 24, p. 31). Nonetheless, Hausknost briefly outlines two other possible escape routes: the first, via the legitimation imperative, is to mount a discursive challenge to the growth imperative through the articulation of a more appealing vision of the lifeworld than what is experienced in consumer capitalist societies. The second is the development of new forms of direct democratic representation and practice within the lifeworld (2020, p. 33).

Dryzek et al's (2003) comparative study of the relationship between green states and environmental movements also rests on five very similar imperatives: (domestic) order, survival, revenue, economic growth, and legitimation. However, unlike Hausknost, Dryzek et al. take a more evolutionary approach and they envision the further expansion of state imperatives if environmental movement demands on the state are successfully hitched to one or more existing imperatives. So, for example, demands for greener technologies (weak, supply-side, technocentric ecological modernisation) and more democratic representation of and attentiveness to environmental concerns (strong, demand-side, more reflexive ecological modernisation) could potentially lead to the development of a green or greener state with a 'conservation' imperative via the workings of the accumulation and legitimation imperatives (Dryzek et al. 2003, Chapter Seven).

Taken together, these critical theories provide a 'dual vision' of the state that recognises not only its enmeshment in capitalist society (national and global) and its need for legitimation but also its own unique selfmaintenance needs to stay afloat. Neo-Weberians recognise the accumulation imperative and neo-Marxists acknowledge the relative autonomy of the state from the capitalist economy. Together, they provide a sobering and challenging starting point for thinking about the state's potential for orchestrating transitions that are transformational. But before examining their prescriptions for breaking the glass ceiling, it is necessary to identify the limits of functionalist theories of the state.

\section{Functionalism and its limits}

The virtue of the foregoing functionalist theories of the state is that they reduce complexity and contingency and strip down state functions to their essential core in order to identify the structural dynamics that impede ecological sustainability. This necessarily entails working at a high level of abstraction in order to provide analytical clarity: core state functions are modelled as a finite set of 'objective imperatives' from a systems viewpoint. Practices of social meaning-making are absorbed within the state's legitimation imperative, which functions mostly (though not exclusively) as an apology given the unavoidable contradictions that must be managed. Since 
no state has succeeded in orchestrating an ecologically sustainable society, both accounts provide an empirically resonant explanation. However, the differences between the accounts also help to expose the limitations of functionalist approaches.

First, which number of state imperatives - two or five - has the most empirical resonance?

Here it is difficult to arbitrate between neo-Marxist and neo-Weberian functionalist theories because any given set of state policy outputs can always be explained in terms of the juggling and management of a pre-given set of imperatives. If a state were to enact sustainability policies that appear inconsistent with existing imperatives then we have no way of testing (and falsifying) whether they should be seen as dysfunctional or a sign of a possible new imperative, and they can always be massaged into an existing imperative.

Second, which account has the most strategic value for approaching ecological transitions? Presumably, neo-Weberian accounts, since more imperatives provide more points of leverage for ecological movements in making demands (not only accumulation and legitimation but also welfare provision, order, survival/security), and more bases for legitimating new initiatives for ecologically enlightened state policy makers. Since the accumulation imperative underpins the growth economy, which undermines sustainability, we might surmise that the more this imperative has to compete with other imperatives, then the more it will have to be circumscribed or redefined to the point that it become compatible with ecological sustainability. However, this argument presupposes that all imperatives have equal weight, and neo-Marxist theories indicate that the accumulation imperative is more fundamental than others, and cannot be overridden, only qualified, by the legitimation imperative (so green growth is possible but a post-growth economy is not).

However, neo-Weberians might argue state survival/security is ultimately more fundamental for state managers. Once the harmful effects of biophysical unsustainability accumulate to the point where they directly endanger the immediate lifeworld of citizens forcing states to respond (a scenario identified by Hausknost) we would expect states to be endangered as well. They would be overwhelmed with demands to cover mounting and uninsurable damage costs in the face of a shrinking revenue base and social unrest. At the very least, we would expect states to anticipate and address looming existential threats to their basic functioning and survival.

Third, presenting core state functions as 'objective imperatives' is necessary from a systems-analytical perspective, since the point is to draw out the structural dynamics that limit how states respond to ecological demands. But it is important not to mistake the systems-analytical map for the territory. All of the accounts discussed above acknowledge that state functions and purposes have evolved and expanded over time. Moreover, they all identify the legitimation imperative as a pathway to breaking the glass ceiling and they 
recognise the importance of discursive framing in managing tensions between functions. However, this recognition requires a shift from an objective structural-functionalist analysis (which explains how social structures are reproduced) towards an analysis of the role of creative political agency in producing new intersubjective meanings (which are sources of political and institutional change). That is, if structural constraints and creative agency are to sit together coherently in the one framework then it is necessary to recast the state's functions as 'historically constituted necessities' rather than a fixed repertoire of 'objective imperatives' to recognise their reification and enable their denaturalisation and politicisation. This is not to deny that the maintenance needs of states, like human basic needs, are real and material, and if unmet carry the risk of serious impairment or death. Rather, it is to argue that such needs may be met in a variety of different ways, and that the range, meaning, and prioritisation of needs, as well as the distinction between core and non-core needs, vary across time and place, and are the subject of political contestation and reinterpretation. As Lund (2016, p. 1200) puts it: "Treating the "state" as a finished product gets in the way of understanding it. The state is always in the making'.

Nonetheless, the structural dynamics highlighted by the foregoing functional analyses cannot be ignored when grappling with the political challenges of transition in capitalist societies. First, states need revenue not only to stay afloat but also to achieve broader purposes, including achieving a just ecological transition. Second, the promotion of economic growth is an historically constituted necessity so the discursive challenge is to figure out how to loosen and dislodge the culturally hegemonic understanding of growth as a necessity to make way for a counter-hegemonic and more reflexive understanding of growth and development that is geared to maintaining the ecological conditions for all life on Earth over time. This could be done, for example, by defending the transition towards ecological sustainability as 'essential to being a state', since it will become increasingly necessary to ensure its survival and the discharge of its other functions. Playing off the tensions between the growth/accumulation function and other functions (such as external security, internal order, revenue raising, and legitimation by safeguarding the welfare of citizens) are ways of limiting and then transforming the accumulation function.

To understand how this might work in practice it is necessary to move towards a less abstract and more dynamic, historicist understanding of the state. A neo-Gramscian theory of the state can serve this purpose. Indeed, many ecological neo-Marxist IPE scholars have drawn on Gramsci's insights in bringing together political ecology and 'cultural political economy' and the semiotic dimensions of hegemonic blocs (e.g. Paterson 2007, Jessop 2010, 2012). Neo-Gramscian theory, which rejects a firm ontological divide between capitalist states and societies while also recognising the relative 
autonomy of the state, can accommodate both structure and agency; it understands the exercise of state power in historically dynamic terms as the institutionally-mediated condensation of the configuration of social forces and hegemonic understandings. It recognises that any societal transformation demands not only new ideas but also hegemonic countermovements, which only become a political force if they can unite around an alternative hegemonic project. This requires discursive articulation and a critical mass of political support (what constitutes a critical mass is shaped, in part, by the relevant political and electoral system). It can also accommodate the fact that different states forms (e.g. welfare states, neoliberal states, developing states) accord different priority to different state functions for different purposes, which provides different opportunities for transformation. Finally, this more historicist understanding of the state provides a fitting framework for addressing the methodological question posed for the critical theory of the green state, which is how to provide practical guidance to state policy makers and other change agents in approaching the transition process in ways that remain critical and transformative. In what follows, a two-step method of conjunctural analysis followed by critical problem-solving is outlined.

\section{A critical method for approaching the transition tensions}

\section{Conjunctural analysis}

For Stuart Hall, a conjuncture is a period during which the different social, political, economic and ideological contradictions that are at work in society come together to give it a specific and distinctive shape' (Hall and Massey 2010, p. 37-46). For John Clarke, it is a 'moment of condensation: an accumulation of tendencies, forces, antagonisms and contradictions' that represents a period of uncertainty and possibility (2010, p. 341). Any given conjuncture is never entirely stable, only more or less stable, whether due to social and political antagonisms, structural contradictions and/or present or impending crisis. A crisis is a critical conjuncture and here I draw on the Greek word krisis, meaning the turning point in a disease which, depending on the response, leads either to recovery or death or serious impairment of the patient. Critical conjunctures (or conjunctural crises), which may be acute or chronic, hold the greatest potential for a systemic reconfiguration, especially when they are a crisis of a social order rather than in a social order (which can be managed by existing crisis management techniques) (Jessop 2012 , p. 19). Some critical conjunctures may be unique to one or only a few states, such as the Arab Spring, while others may be confronted by many or most states in different ways, such as the 2007-2008 global financial crisis (GFC) and COVID-19 pandemic (discussed further below). However, much 
depends on the framing of the conjuncture and the response. As Blyth (2002, p. 251) demonstrates in his analysis of the great economic transformations of the 20th century, 'institutional change only makes sense by reference to the ideas that inform agents' responses to moments of uncertainty and crisis'. This applies as much to governments as to business, nongovernment organisations and social movements. It also depends on which social agents have access to, and influence over, the relevant policy makers at the crucial time.

Conjunctural analysis within a particular state-society complex entails surveying the conjuncture, including the 'complex field of power and consent and looking at its different levels of expression - political, ideological, cultural and economic' (Hall and Massey 2010, p. 66). This includes structural injustices, hierarchies of knowledge and dominant discourses but also tensions, cracks, contradictions in these arrangements, and the double movements and counter-hegemonic discourses that emerge in response. As Clark notes, it is dangerous and unhelpful to assume hegemonic projects are completely successful; indeed, political success can be precarious and it is typically incomplete, so fixating only on what is dominant can conceal subordinations and other possible trajectories (2010, p. 359). The aim of conjunctural analysis here is to identify the political opportunities (and dangers) that are presented for ecological transition, including sites within the state and civil society or intermediaries (parties, social networks etc,) that hold the most potential for new transition initiatives. It provides the necessary groundwork for the more practical and situated task of critical problemsolving.

\section{Critical problem-solving}

One unfortunate and unintended consequence of Cox's distinction between critical theory and 'mere' problem-solving is that it carries the implicit assumption that the latter is something critical theorists should avoid, since critical theory must stay focused on all social structures that combine to produce or 'over-determine' socio-ecological injustices. Yet if it is politically impossible to restructure everything at once (short of a whole of society revolution or major external shock) and anything less is problem-solving (to be feared due to loss of criticality) then this renders critical theory unable to realise its practical emancipatory intent. As Ricardo Blaug has put it (albeit in a slightly different context), critical theory remains 'caught in a twilight zone between fear and disappointment. It has practical intentions which it knows it must not [and cannot] fulfil' (Blaug 1997, p. 117, author's interpellation).

Critical problem-solving seeks to rescue the critical theory of the green state from this aporia so it can make a practical contribution to the transition process. It is offered not as a set of substantive prescriptions but rather as an approach to the transition challenge to assist policy makers and policy 
advocates who are seeking to build political traction for transformational changes. That is, it is problem-solving in the service of transformation. It therefore assumes a normative commitment to transition policies, processes and pathways that entail restructuring, and recognises this entails social dislocation and is likely to generate political conflict if not anticipated and addressed. It also assumes a commitment to the principles of just transition (discussed further below), given the centrality of justice to CPE.

If uncritical problem-solving is like puzzle-solving, which accepts the fixed parameters set by the puzzle, then critical problem-solving looks for ways to unsettle at least some of these parameters as a first step, with a view to challenging others in subsequent steps. This requires provisionally bracketing some problematic social structures, recognising that not all can be tackled fully and at once (Eckersley 2020, p. 4; see also Mahmoud et al. 2018). Critical problem-solving necessarily takes place in political contexts that are structurally unjust and communicatively distorted, so the practical task is to identify the next best transition steps with the greatest transformative potential in the relevant context, guided by conjunctural analysis. 'Next best' means the best of the politically possible next steps. Depending on the political opportunities presented by the conjuncture, in some cases the next best steps may be small and incremental, while in other cases there may be opportunities for larger leaps. Either way, critical problem-solving needs to remain attentive to the limits of human understanding of the full range of consequences of any policy intervention. The judgment about whether the next steps will indeed prove to be the best cannot be fully known ex ante. The virtues of a step-wise approach is that it enables scaling up (or back) and adaptation ex post as a result of political and policy learning.

Critical problem-solving has some significant points of overlap with the literature on socio-technical transition management, which is geared to ensuring goal attainment by avoiding capture and co-optation by incumbent interests (such as the fossil fuel industry and state agencies that are captured by these industries). Transition management prescribes a series of steps that include nurturing societal networks of innovation in relation to a particular socio-technical system in safe spaces (the niche), excluding incumbent actors to avoid co-option and then expanding and empowering the network, addressing regulatory barriers and ensuring a process of ongoing reflexive learning (Loorbach 2010). This approach also recognises that it is not enough to nurture and build support for new sustainable regimes; it is also necessary to develop policy mixes that simultaneously destabilise and phase-out the unsustainable incumbent regimes since their continued presence can thwart the expansion of new regimes (e.g. Kivimaa et. al 2016). The transition management research is clearly problem-solving in the sense that it has developed practical guidelines for facilitating transitions, and also critical in its attentiveness to the threat of capture and co-optation. These are 
important insights for critical problem-solving. However, there are three points of differentiation between these approaches.

First, from a transition management perspective, success is achieved when the transition goals of the particular innovation network are met. However, as noted above in the discussion of the distinction between transition and transformation, these goals may not necessarily be geared towards a broader societal transformation and they may even make it harder to achieve such a transformation in the absence of coordination with other transitions. Nor is this perspective geared towards social inclusion and broad democratic participation (Hendriks 2009).

Second, socio-technical transition scholars have not made the state their central focus of analysis and, as Johnstone and Newell (2018) have shown, their understanding of the state is under-developed. While politics, power and policy making have become much more prominent in research on sociotechnical systems (e.g., Geels 2019, Köhler et al. 2019), the primary unit of analysis remains transitions of socio-technical systems, not the mutual transformation of states and societies. Nor does it have a critical normative vision of what states should become, and what might be an appropriate symbiosis between states, societies and social networks of innovation.

Third, the transition management literature has not grappled with the more general political challenge of moving to a post-growth society. This includes the democratic challenge of winning sufficient political support for such a shift and managing the social dislocations associated with multiple transitions. Indeed, Köhler et al. (2019, p. 10) has conceded in his comprehensive stocktaking of the field of socio-technical transition studies that it has only recently turned its attention to questions of distributive justice.

In contrast, critical problem-solving is aligned with the just transition movement, which approaches the transition process in a more holistic way as a collective societal responsibility rather than a socio-technical challenge (e.g. Harrahill and Douglas 2019). It is also more critical of capitalist relations as exploitative of workers, broader communities and environments (e.g. Healy and Barry 2017). Moreover, the understanding of justice in just transition has many dimensions that go beyond distributive justice to include procedural justice (inclusive participation), restorative justice (compensating dislocated workers and communities) and more inclusive forms of recognition of socioecological communities. The state is also recognised as playing a central role in making a just transition possible. This includes providing public recognition of, and responsibility for, the dislocation suffered by affected communities; public compensation and/or retraining for workers; and new infrastructure and urban or regional development policies to foster ecologically sustainable work (Healy and Barry 2017,p. 455, Harrahill and Douglas 2019).

Of course, it is always a political challenge to bring all good things together. As Ciplet and Harrison (2019) have shown, the principles of just 
transition contain internal tensions. These include the need for boldness, timeliness, and goal achievement to minimise future social and environmental injustices versus socially inclusive policy making processes (which are time-consuming and often conflict-ridden), recognition of diverse value systems and rights, and the equitable distribution of benefits and burdens to existing generations. To this we may add that the principles of just transition presuppose sufficient administrative and financial capacity at the national and/or subnational levels to enable governments to provide structural adjustment, but this capacity may be limited. While it is politically impossible to achieve all principles fully and at once, no single principle should be fully sacrificed at the expense of any other, because they are essential to addressing the injustices associated with restructuring, building political support and ensuring politically successful transitions.

It is beyond the scope of one paper or one person to provide a comprehensive working through of the demanding steps of conjunctural analysis and critical problem-solving, which must necessarily be situated in time and place. Indeed, Clarke (2018, p. 84) warned that conjunctural analysis 'is not something that should be undertaken alone'. The same applies to critical problem-solving, which needs to be debated and tested from different social standpoints to anticipate problems and objections and find ways of addressing them to attract sufficient political support. Nonetheless, to round out the discussion I offer a brief illustrative sketch of how conjunctural analysis and critical problem-solving might be applied to challenges of ecological transition in the wake of the coronavirus pandemic. The standpoint adopted is that of a national policy maker seeking to align economic recovery with ecological transition in transformational ways.

\section{Illustration: pandemic recovery}

The coronavirus pandemic represents a major critical conjuncture that carries significant new dangers and opportunities for transition. After many decades of so-called retreat (i.e. from the welfare state to the competition state), the immediate response to the pandemic was a dramatic expansion of the state's welfare function relative to the accumulation function. This included the rapid closure of many businesses, major restrictions on social mobility and new welfare payments and stimulus measures to address growing unemployment. These measures have been widely legitimated by governments of varying persuasions as necessary to 'protect lives and livelihoods', and signal a (temporary) social protection function for acute emergency situations. In many (though not all) jurisdictions, governments of various ideological persuasions have turned to expert medical advice and the conservative and neoliberal attachment to fiscal austerity was temporarily suspended. The rising rate of COVID-19 infections phase of the pandemic 
may be understood as an acute crisis in (rather than of) the social order, since there are well-established health crisis management institutions and techniques available.

However, the more significant critical conjuncture is presented not by the pandemic but rather by the so-called economic recovery phase, which represents an ongoing, chronic critical conjuncture of the social order because it entails systemic risks (financial, social and ecological) and exposes the limitations of existing management techniques. There are many elements to this critical conjuncture that are most relevant to the transition challenge. On the negative side, states are amassing spiralling levels of debt on top of the GFC debt legacy, which will be difficult for many states to service. This increases the risk of systemic financial crises and collapse. Unemployment has climbed dramatically and is expected to stay high, leading to growing social unrest. Many businesses are seeking government assistance, including tax breaks and a weakening of environmental regulation. The pandemic also arrived in a critical year for the Paris Agreement 2015, where parties were expected to update the first round of nationally determined contributions that run to 2030, and also develop and post their long-term strategies to reduce net emissions to zero by 2050 . If developed states fail to make their economic recovery plans compatible with deep emissions cuts over the next decade, and fail in their obligation to scale up their contributions to climate finance to assist developing countries over the period 2020-2025, then the prospects of holding global heating to 1.5 degrees Celsius will vanish.

On the positive side, the dislocation of many global supply chains has raised the prospect of a turn towards more local and regional supply chains, especially in critical areas of social provisioning such as food and other essential supplies. Global emissions have dropped precipitously (albeit temporarily), but enough to reveal dramatic improvements in air and water quality in many major cities, signalling the local health, amenity, and biodiversity benefits of reducing emissions. The fall in oil prices enhances the prospects of dismantling fossil fuel subsidies while providing a window for new or higher carbon taxes that will be less regressive compared to periods of higher oil prices. The demonstration of the importance of expert advice during the pandemic has the potential to blunt the denial of climate science by conservatives while the state's function in emergencies to 'protect lives and livelihoods' can be easily extended to sudden onset climatic events such as fires, storms, and floods.

Of crucial importance, however, are the discourses and policies of 'economic recovery'. These range widely, from a 'snap back' to the old normal (such as in Australia) to a recovery strategy based on green stimulus packages, green growth or a green new deal (GND) (such in the EU and the US, advocated by the Sunrise movement) and more radical discourses of glocalisation and/or degrowth. Yet the lessons from the green stimulus 
packages applied during the GFC are salutary. For example, Tienhaara's comparative study of these packages in five OECD countries found that there was no substantial green shift in government spending and no significant improvement in actual environmental conditions (Tienhaara 2018, p. 142; see also Jessop 2012). In short, none of the policy measures taken in response to the GFC were transformational and they all harked back to the Keynesian state, rather than look forward to a greener state and a postgrowth economy. Overall, Tienhaara concluded that this was a 'waste of a good crisis'.

Given these lessons, critical problem-solving must go beyond a purely pragmatic strategy of green growth that leaves unsustainable industries intact. Yet orchestrating an indiscriminate economy-wide strategy of degrowth in the context of a major recession is no less problematic (albeit in different ways) than orchestrating indiscriminate, economy-wide growth. It is not the next best step with the greatest transformative potential because it would generate a significant political backlash, produce particularly harsh economic consequences for the most marginal members of society, and set back the transition process. It would weaken the state's general functional capacity across the board, including its capacity to build just transition institutions and policies, which is much harder to manage on an economy-wide scale than a regional or local scale. Instead, a first-step that combines a strategy of green growth and stimulus spending on green infrastructure with a sequenced phase-out of the most emissions intensive and ecologically harmful industries would enable the restructuring to start where it is most needed. It would also create opportunities for new regional economic development strategies and policies aimed at more localised and sustainable production, employment and consumption in critical areas of provisioning (energy, food, water, transport, medical supplies) to ensure greater community preparedness and resilience to future pandemics and global heating impacts. Local participation and experimentation in new co-operative forms of provisioning can also build local commitment and enable ongoing reflexive learning. More generally, transition can be enhanced by the creation and/or funding of dedicated transition institutions, such as Spain's 'Ministry for Ecological Transition', or the national, not-for-profit 'Transition Accelerator' developed for Canada by Meadowcroft et al. (2019).

We saw in the previous section that the state's legitimation function is a key pathway to breaking the glass ceiling on socio-ecological transformation. But the next best discourses to legitimate socio-ecological recovery and transition need to be 'step-wise' in the sense of maintaining sufficient connection with social understandings and experiences while also critically stretching them. Responses to emergencies reveal state and societal priorities, and we saw that many state responses to the pandemic involved a dramatic expansion and prioritisation of the state's welfare or social protection function in defence of 'lives and livelihoods'. The increasing harmful impacts of global heating will produce many 
more emergencies, alongside slower-onset harms, that will endanger lives, livelihoods and ecological communities. Discourses that bring these growing risks into view and distinguish between healthy and life-affirming versus unhealthy and life-destructive human development are likely to resonant much more with publics than the politically unproductive binary between economic growth versus degrowth. It also enables the unbundling of growth into that which enables sustainable production and consumption and that which does not. This directs attention away from growth in monetary terms to growth in ecological protection, equality, and human need satisfaction (Gough 2017, Koch 2020, p. 123-24). Further restructuring over time depends upon an expansion and prioritisation of the state's environmental and welfare functions to maintain an ongoing just transition strategy on a societal scale. This requires an expanding revenue base, which could be garnered, for example, from higher and more comprehensive environmental and climate-related taxes and charges on industry and more progressive taxation to address extreme income and wealth differentials. In short, just ecological transitions in the service of green transformations demand an expanded role for the state, including a greater role for planning and economic restructuring, and much more extensive wealth and income redistribution to enable a post-growth society that no longer relies on material-energy growth to address inequality.

\section{Conclusion}

As Schmidz (2015, p. 179) has observed, the great green transformation is the first great transformation in history that must be achieved purposely in accordance with a deadline. Purposive transformations need to be planned but they cannot be fully planned and realised by any single orchestrator. Nonetheless, states are better placed than any other actor or organisation to facilitate socio-ecological transformation given their powers to regulate, tax, spend, redistribute, and procure and to perform these tasks in ways that are more or less responsive and accountable to citizens. But not all states have the same capacity and/or motivation to perform this role. Conjunctural analysis is a means of determining where opportunities may lie in particular state-society complexes, including whether different political parties, branches or agencies of the state can be allies in the transition process, and to what extent non-state actors and local communities offer complementary or alternative potential. Critical problem-solving follows through by thinking through how best to develop these opportunities to initiate new transition pathways or amplify and accelerate the momentum of transitions that are already underway. It looks for opportunities with the greatest political potential to 'reconfigure the conjuncture' in the general direction of green transformation. Fostering innovation and experimentation in social organisation, and new discursive designs to debate and address transition tensions 
and pathways in ways that do not privilege powerful vested interests, should receive at least as much attention as technical innovation. This applies at all scales for societal transformations, but states are crucial to enabling just transitions on a societal scale. Finally, developed states must step up their commitment to contribute to the Green Climate Fund which represents the closest existing approximation of an international just transition fund for developing states.

\section{Acknowledgments}

I wish to thank the Swedish Research Council for awarding me the Kerstin Hesselgren Visiting Professorship at Lund University in 2019 where the bulk of the research for this paper was conducted. I am especially grateful to Annica Kronsell for organising the Kerstin Hesselgren grant application, to Johannes Stripple for welcoming me and helping to manage my stay, and to the Department of Political Science for their warm hospitality. I am grateful for feedback on earlier versions of this article from the participants in the Workshop on The Great Green Transformation at the NESS conference at Luleå, Sweden in June 2019, and to participants at the Environmental Politics Workshop at Spetses, Greece in July 2019. Many thanks also to Peter Christoff, Daniel McCarthy and especially James Meadowcroft for helpful comments on earlier drafts.

\section{Disclosure statement}

No potential conflict of interest was reported by the author(s).

\section{Funding}

This work was supported by the Vetenskapsrådet [Kerstin Hesselgren Visiting Professor 2019].

\section{ORCID}

Robyn Eckersley (D) http://orcid.org/0000-0002-3410-7186

\section{References}

Bäckstrand, K. and Kronsell, A., eds., 2015. Rethinking the green state: towards climate and sustainability transitions. Abingdon: Routledge.

Bailey, D., 2015. The environmental paradox of the welfare state: the dynamics of sustainability. New Political Economy, 20 (6), 793-811. doi:10.1080/ 13563467.2015.1079169

Bailey, D., 2020. Re-thinking the fiscal and monetary political economy of the green state. New Political Economy, 25 (1), 5-17. doi:110.1111/1467-9248.00074

Blaug, R., 1997. Between fear and disappointment: critical, empirical and political uses of Habermas, Political Studies, 45, 100-117. doi:10.1080/13563467.2018.1526267. 
Blyth, M., 2002. Great transformations: economic ideas and institutional change in the twentieth century. New York: Cambridge University Press.

Castree, N., 2008. Neoliberalising nature: the logics of deregulation and reregulation. Environment and Planning A, 40 (1), 131-152. doi:10.1068/a39100

Cerny, P.G., 2010. The competition state today: from raison d'etat to raison $d u$ monde. Policy Studies, 31 (1), 5-21. doi:10.1080/01442870903052801

Ciplet, D. and Harrison, J.L., 2019. Transition tensions: mapping conflicts in movements for a just and sustainable transition. Environmental Politics. doi:10.1080/ 09644016.2019 .1595883

Clarke, J., 2010. Of crises and conjunctures: the problem of the present. Journal of Communication Inquiry, 34 (4), 337-354. doi:10.1177/0196859910382451

Clarke, J., 2018. Doing the dirty work: the challenges of conjunctural analysis. In: J. Henriques and D. Morley, eds.. Stuart Hall: conversations, projects and legacies. London: Goldsmiths, 79-85.

Cox, R., 1981. Social forces, states and world order: beyond IR theory. Millennium: Journal of International Relations, 10 (2), 126-155.

Douglas, R.N., 2020. The 'glass ceiling' of the environmental state and the social denial of mortality. Environmental Politics, 29 (1), 58-75. doi:10.1080/ 09644016.2019.1685218

Dryzek, J.S., et al., 2003. Green states and social movements. Environmentalism in the United States, United Kingdom, Germany, and Norway. Oxford: Oxford University Press.

Eckersley, R., 2004. The green state: rethinking democracy and sovereignty. Cambridge, MA: MIT Press.

Eckersley, R., 2020. The green state in transition: reply to Bailey, Barry and Craig'. New Political Economy, 25 (1), 46-56. doi:10.1080/09644016.2019.1594536

Geels, F., 2019. Socio-technical transitions to sustainability: a review of criticisms and elaborations of the multi-level perspective. Current Opinion in Environmental Sustainability, 39, 187-201. doi:10.1016/j.cosust.2019.06.009

Gough, I., 2017. Heat, greed and human need: climate change, capitalism and sustainable wellbeing. Cheltenham: Edward Elgar.

Hall, S. and Massey, D., 2010. Interpreting the crisis. Soundings, 44, 57-71.

Harrahill, K. and Douglas, O., 2019. Framework development for 'just transition' in coal producing jurisdictions. Energy Policy, 134, 1-11. doi:10.1016/j.enpol.2019.110990

Hausknost, D., 2020. The environmental state and the glass ceiling of transformation. Environmental Politics, 29 (1), 17-37. doi:10.1080/09644016.2019.1680062

Hausknost, D. and Hammond, M., 2020. Beyond the environmental state? The political prospects of a sustainability transformation. Environmental Politics, 29 (1), 1-16. doi:10.1080/09644016.2020.1686204

Healy, J. and Barry, J., 2017. Politicizing energy justice and energy system transitions: fossil fuel divestment and a "just transition". Energy Policy, 108, 451-459. doi:10.1016/j.enpol.2017.06.014

Hendriks, C., 2009. Policy design without democracy? Making democratic sense of transition management. Policy Sciences, 42 (4), 341-368. doi:10.1007/s11077-0099095-1

Hickel, J. and Kallis, G., 2019. Is green growth possible? New Political Economy. doi:10.1080/13563467.2019.1598964

Hysing, E., 2015. Lost in transition? The green state in governance for sustainable development'. In: K. Bäckstrand and A. Kronsell, eds. Rethinking the green state: towards climate and sustainability transitions. Abingdon: Routledge, 27-42. 
Jessop, B., 2010. Cultural political economy and critical policy studies. Critical Policy Studies, 3 (3-4), 336-356. doi:10.1080/19460171003619741

Jessop, B., 2012. Economic and ecological crises: green new deals and no-growth economies. Development, 55 (1), 17-24. doi:10.1057/dev.2011.104

Johnstone, P. and Newell, P., 2018. Sustainability transitions and the state. Environmental Innovation and Societal Transitions, 27 (72-82). doi:10.1016/j. eist.2017.10.006

Katz-Rozene, R. and Paterson, M., 2018. Thinking ecologically about the global political economy. Abingdon: Routledge.

Kivimaa, P. and Kern, F., 2016. Creative destruction or mere niche support? Innovation policy mixes for sustainability transitions. Research Policy, 45 (1), 205-217. doi:10.1016/j.respol.2015.09.008

Koch, M., 2020. The state in the transformation to a sustainable postgrowth economy. Environmental Politics, 29 (1), 115-133. doi:10.1080/09644016.2019.1684738

Köhler, J., et al., 2019. An agenda for sustainability transitions research: state of the art and future directions. January, 27 (May), 2019. Available at: https://transitions network.org/about-strn/research_agenda/

Linnér, B.-O. and Wibeck, V., 2019. Sustainability transformations: agents and drivers across societies. Cambridge: Cambridge University Press (in press).

Loorbach, D., 2010. Transition management for sustainable development: a prescriptive, complexity-based governance framework. Governance: An International Journal of Policy, Administration, and Institutions, 23 (1), 161-183. doi:10.1111/j.14680491.2009.01471.x

Lund, C., 2016. Rule and rupture: state formation through the production of property and citizenship. Development and Change, 47 (6), 1199-1228. doi:10.1111/dech.12274

Mahmoud, Y., et al., 2018. At the nexus of problem-solving and critical research. Ecology and Society, 23 (4), 40. doi:10.5751/ES-10458-230440

Meadowcroft, J., 2005. Environmental political economy, technological transitions and the state. New Political Economy, 10, 479-498. doi:10.1080/ 13563460500344419

Meadowcroft, J., Layzel, D., and Mousseau, N., 2019. The transition accelerator: building pathways to a sustainable future. Available from: https://www.cesarnet. $\mathrm{ca} /$ publications/transition-accelerator-reports/transition-accelerator-buildingpathways-sustainable.

Mol, A.P.J., 2016. The environmental nation state in decline. Environmental Politics, 25 (1), 48-68. doi:10.1080/09644016.2015.1074385

Paterson, M., 2007. Automobile politics: ecology and cultural political economy. New York: Cambridge University Press.

Paterson, M., 2016. Political economy of greening the state. In: T. Gabrielson, et al., eds. The Oxford handbook of environmental political theory. Oxford: Oxford University Press, 1-17 (online version).

Polanyi, K., 1944-2001. The great transformation: the political and economic origins of our time. Boston: Beacon Press.

Schmidz, H., 2015. Green transformation: is there a fast track? In: I. Scoones, M. Leach, and P. Newell, eds. The politics of green transformations. Abingdon: Routledge, 170-184.

Scoones, I., Leach, M., and Newell, P., eds., 2015. The politics of green transformations. Abingdon: Routledge. 
Stirling, A., 2015. Emancipating transformations: from controlling 'the transition' to culturing plural radical progress. In: I. Scoones, M. Leach, and P. Newell, eds. The politics of green transformations. London, UK: Routledge, 54-67.

Tienhaara, K., 2018. Green Keynesianism and the global financial crisis. London: Taylor and Francis. 


\section{University Library}

\section{- M M I N E R VA A gateway to Melbourne's research publications}

Minerva Access is the Institutional Repository of The University of Melbourne

Author/s:

Eckersley, R

Title:

Greening states and societies: from transitions to great transformations

Date:

2020-08-30

Citation:

Eckersley, R. (2020). Greening states and societies: from transitions to great transformations. Environmental Politics, 30 (1-2), pp.1-21. https:// doi.org/10.1080/09644016.2020.1810890.

Persistent Link:

http://hdl.handle.net/11343/260523

License:

CC BY 